\title{
Analyst
}

\section{Highlighting a need to distinguish cell cycle signatures from cellular responses to chemotherapeutics in SR-FTIR spectroscopy}

\author{
C. Hughes, ${ }^{a b}$ M. D. Brown, ${ }^{b}$ F. J. Ball, ${ }^{a}$ G. Monjardez, ${ }^{a}$ N. W. Clarke, ${ }^{b}$ K. R. Flower ${ }^{c}$ and P. Gardner ${ }^{* a}$ \\ Received 14th May 2012, Accepted 10th October 2012 \\ DOI: 10.1039/c2an35633c
}

\begin{abstract}
Previous research has seen difficulties in establishing clear discrimination by principal component analysis (PCA) between drug-treated cells analysed by single point SR-FTIR spectroscopy, relative to multisampling cell monolayers by conventional FTIR. It is suggested that the issue arises due to signal mixing between cellular-response signatures and cell cycle phase contributions in individual cells. Consequently, chemometric distinction of cell spectra treated with multiple drugs is difficult even with supervised methods. In an effort to separate cell cycle chemistry from cellular response chemistry in the spectra, renal carcinoma cells were stained with propidium iodide and fluorescent-activated cell sorted (FACS) after exposure to a number of chemotherapeutic compounds; 5-fluorouracil (5FU) and a set of novel gold-based experimental compounds. The cell spectra were analysed separately by PCA in $\mathrm{G}_{1}$, $\mathrm{S}$ or $\mathrm{G}_{2} / \mathrm{M}$ phase. The mode of action of established drug $5 \mathrm{FU}$, known to disrupt $\mathrm{S}$ phase, was confirmed by FACS analysis. The chemical signature of 5FU-treated cells discriminated against both the control and gold-compound (KF0101)-treated cell spectra, suggesting a different mode of action due to a difference in cellular response.
\end{abstract}

\section{Introduction}

SR-FTIR spectra of cells treated with different agents have been difficult to discriminate with the use of principal component analysis (PCA), although it has been suggested that there may be small sub-clusters where spectra are grouping due to their cell cycle signatures. ${ }^{1}$ A typical collection of SR-FTIR spectra from a cell population will yield a mixture of spectra displaying different quantities of biomolecular component bands, depending on the phase of the cell at the time of data acquisition. ${ }^{2}$

It is possible to sort and collect cells through the use of a fluorescence-activated cell sorting (FACS) which analyses the DNA content of the cell by use of a fluorescent dye that quantitatively binds to DNA. Propidium iodide (PI) stoichiometrically binds to double-stranded DNA through intercalation, a process through which particular ligands fit between the base pairs of DNA, leading to DNA conformational changes. ${ }^{3}$

Cells in $\mathrm{G}_{1}(\mathrm{Gap} 1)$ are in a post mitotic phase undergoing cell growth and organelle synthesis in preparation for cell division.

\footnotetext{
${ }^{a}$ Manchester Interdisciplinary Biocentre, University of Manchester, 131 Princess Street, Manchester, UK M1 7DN. E-mail: peter.gardner@, manchester.ac.uk

${ }^{b}$ Genito-Urinary Cancer Research Group, School of Cancer and Enabling Sciences, Paterson Institute for Cancer Research, University of Manchester, The Christie NHS Foundation Trust, Manchester Academic Health Sciences Centre, Manchester, UK, M20 4BX

'School of Chemistry, University of Manchester, Manchester, M13 9PL, UK
}

The cells in the S phase are actively undergoing DNA-synthesis and contain increasing quantities of DNA. The post DNAsynthesis phase is referred to as $G_{2}$, where cells have twice the amount of DNA as in the $\mathrm{G}_{1}$ phase, prior to entering into mitosis (M phase). ${ }^{4}$

The use of PI for cellular spectral analysis and PCA discrimination will lead to an obvious cluster separation of the cells from different phases, as presumably the extent of DNA conformational changes increases as a function of increasing PI concentration. Given that the staining reaction mechanism is stoichiometric, (i.e. cells in $\mathrm{G}_{1}$ will have 1 genome labelled by PI whereas cells in $G_{2}$ will have 2 genomes labelled), it should be possible to compare a single cell line treated with multiple agents under the caveat that comparative analysis is performed in one cell cycle phase for a given time. It is proposed that the PI concentration per cell cycle phase is relatively constant for an individual cell line and therefore any PI staining in spectral terms may be omitted as a consequence of cluster separation.

The novel therapeutic gold-based compound KF0101 (KF1) and analogues KF0113 and KF0501 were assessed for efficacy against a renal cell carcinoma cell model (A-498). ${ }^{5}$ 5-Fluorouracil (5FU) an established chemotherapeutic agent with known modes of action was also evaluated. The compounds were tested on their ability to affect cell cycle by FACS at their experimental $\mathrm{IC}_{25}$ and $\mathrm{IC}_{50}$ levels. Following cell sorting, untreated cells and cells treated with $\mathrm{KF} 1$ and $5 \mathrm{FU}$ were deposited on IR-transparent substrates for SR-FTIR spectroscopic analysis. 


\section{Methods and materials}

\section{Cell culture}

The A-498 renal carcinoma cell line was cultured in DMEM with FCS $(15 \%)$ and L-glutamine $(1 \%)$ at $37{ }^{\circ} \mathrm{C}$ in a humidified atmosphere $\left(5 \% \mathrm{CO}_{2}\right)$.

\section{Cytotoxicity assay}

Inhibitory concentration $\left(\mathrm{IC}_{50}\right)$ values for each agent were determined by the Sulforhodamine B (SRB) assay as described by Vichai and Kirtikara. ${ }^{6}$ Cells were seeded at a pre-defined density (3000 cells in $100 \mu \mathrm{L}$ medium per well) in triplicate and left for 24 hours to ensure cells were well-established and adhered to the bottom of the well plate. A range of $12 \mathrm{drug}$ concentrations between 0.15 and $20.0 \mu \mathrm{M}$ were used by the addition of drug/media ( $100 \mu \mathrm{L}$ at twice the desired concentration) to the established cells in media $(100 \mu \mathrm{L})$ giving the correct final concentration range. For the control group, media only was added $(100 \mu \mathrm{L})$. The well plates were incubated at $37{ }^{\circ} \mathrm{C}$ for 3 days in $5 \% \mathrm{CO}_{2}$ in air. After 3 days the well solution was discarded and wells washed with PBS $(\times 2100 \mu \mathrm{L})$. The remaining cells were fixed with TCA $\left(100 \mu \mathrm{L} ; 10 \%\right.$ w/v $\left.\mathrm{H}_{2} \mathrm{O}\right)$, $4{ }^{\circ} \mathrm{C}$ for $1 \mathrm{~h}$. The wells were washed with PBS $(\times 2100 \mu \mathrm{L})$ and dried at room temp. (RT) for 1-2 hours. The cells were stained with SRB $\left(100 \mu \mathrm{L} ; 0.4 \% \mathrm{w} / \mathrm{v} \mathrm{H}_{2} \mathrm{O}\right)$ and left for 15 minutes at RT. The plates were then washed with acetic acid $\left(1 \% \mathrm{w} / \mathrm{v} \mathrm{H}_{2} \mathrm{O}\right)$ until the acid ran clear and dried at RT for 1-2 hours. The protein residues were then re-suspended with Tris- $\mathrm{HCl}(100 \mu \mathrm{L} ; 1.5 \mathrm{M}$; $\mathrm{pH}$ 8.8) with agitation on a shaker for 5 minutes before reading on a Versamax plate reader (Molecular Devices) at $490 \mathrm{~nm}$ absorbance.

Each experiment was repeated in triplicate and average absorbance values were calculated. The data was exported to Graphpad Prism, for normalisation and plotted in the logarithmic form to determine the $\mathrm{IC}_{50}$ values for each agent (Fig. 1). These were calculated as; KF1 [2.61 $\mu \mathrm{M}]$; KF13 [2.23 $\mu \mathrm{M}]$; KF5 [3.26 $\mu \mathrm{M}] ; 5 \mathrm{FU}[2.91 \mu \mathrm{M}]$.
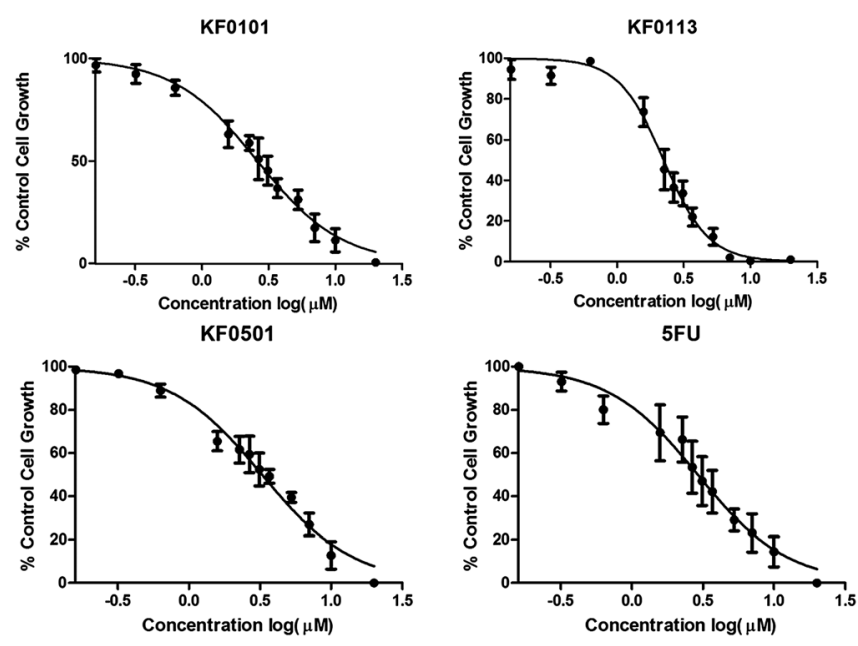

Fig. 1 Dose-response curves with mean values \pm standard error from triplicate experiments to determine $\mathrm{IC}_{50}$ values for the A-498 cell line from the SRB assay data.

\section{Fluorescent activated cell sorting}

A-498 cells were seeded at $5 \times 10^{5}$ cells in Falcon (T25) flasks. After 24 hours agents KF0101, KF0113, KF0501 and 5FU were added at $\mathrm{IC}_{25}$ and $\mathrm{IC}_{50}$ and left for 24 and 72 hours. For the control group no agent was added to the cells. After the appropriate time the media from each flask, containing dead cells, was removed. The remaining adherent, viable cells were washed with PBS. The cells were trypsinised and centrifuged. The cell pellet was re-suspended in the smallest possible volume of PBS and agitated. PBS $(1 \mathrm{~mL})$ was added to the cell suspension, transferred to Eppendorf tubes and spun $(800 g ; 5 \mathrm{~min})$. The supernatant was aspirated and the Eppendorf agitated to break up the pellet. Ice cold EtOH $\left(1 \mathrm{~mL} ; 70 \%\right.$ in $\left.\mathrm{H}_{2} 0\right)$ was added and the Eppendorf vortexed to prevent cell clumping. The cells were fixed in $\mathrm{EtOH}$ for $30 \mathrm{~min}$ at RT. ${ }^{7,8}$ Cells were adjusted to approximately $5 \times 10^{5}$ cells $\mathrm{mL}^{-1}$ and washed twice in PBS (1\% BSA). Cells were spun $(1000 g ; 5 \mathrm{~min})$ and re-suspended in staining buffer $(1 \mathrm{~mL})$ comprised of propidium iodide $\left(50 \mathrm{mg} \mathrm{mL}^{-1}\right)$, Triton-X (0.1\% v/v), PBS and ribonuclease A $\left(50 \mathrm{mg} \mathrm{mL}^{-1}\right)$. Cells were incubated at RT for 20 minutes, protected from light. The cells were sorted using an Influx FACS analyser.

\section{SR-FTIR measurements and processing}

Following cell sorting, cells were spun and re-suspended in $150 \mu \mathrm{L}$ of $\mathrm{H}_{2} \mathrm{O}$. The cells were deposited onto $\mathrm{CaF}_{2}$ substrates at $800 \mathrm{~g}$ for 5 minutes using a Thermo Shandon Cytospin 3. Samples included cells treated with $5 \mathrm{FU}$ and $\mathrm{KF} 1$ at $\mathrm{IC}_{50}$ concentrations for 24 hours and 72 hours after agent introduction. Untreated cells were also sorted as a control for both time periods.

SR-FTIR transmission spectra were acquired on the SMIS beamline of the French Synchrotron Facility SOLEIL (SaintAubin, France) using a Nicolet Continuum XL microscope equipped with an MCT detector. ${ }^{9}$ Spectra were recorded at $4 \mathrm{~cm}^{-1}$ resolution with $256 \mathrm{co}$-scans and the size of the aperture was adjusted to match the diameter of the cells to ensure full illumination. The day 1 control dataset contained 73 spectra in total and the day 3 dataset (control, 5FU treated or KF1 treated cell spectra) contained 113 spectra. All the spectra were affected, to a greater or lesser extent, by resonant Mie scattering. ${ }^{10}$ This causes distortions of the baseline, asymmetries in band shape and shifts in band position. ${ }^{11}$ The raw spectra were, therefore, corrected with a Matrigel ${ }^{\mathrm{TM}}$ reference spectrum and 100 iterations of the RMieS-EMSC algorithm. ${ }^{11}$ Cell spectra were analysed using the fingerprint region by vector-normalised, mean-centred PCA, performed in Matlab (Mathworks Inc.).

\section{Results and disussion}

\section{FACS cell cycle analysis}

Cells were FACS sorted post PI staining for cell cycle analysis for two time-points ( 24 and 72 hours) after initial exposure to the agents KF1 (and KF13, KF5) and 5FU at similar IC $_{50}$ concentrations. There were no observable differences between the untreated control cells and the KF-agents during both time periods.

$5 \mathrm{FU}$ is said to inhibit cell cycle progression at $\mathrm{S}$ phase, ${ }^{\mathbf{1 2}}$ however there was no apparent change in the FACS cell cycle 
profile until 72 hours after drug addition (Fig. 2d). 5FU did not have an immediate 'observable' effect on the cell population 24 hours after drug addition. Initial drug activity would have affected cells in $G_{1}$ not commited to $S$, however all remaining cells will have gone through the remainder of the cycle and $G_{1}$ before being disrupted in $\mathrm{S}$ where $5 \mathrm{FU}$ is known to block DNA synthesis. ${ }^{12}$ After 72 hours of drug addition the cell population has had time to complete its phase cycle. The count of 5FUexposed cells distinctly increased between $\mathrm{G}_{1}$ and $\mathrm{S}$, highlighting the phase-specific disruptive capabilities of 5FU (Fig. 2d).

\section{Assessment of control cell cycle spectra}

Optical images of the FACS-sorted control cells, cytospun onto calcium fluoride substrates are displayed in Fig. 3. The $\mathrm{S}$ and $\mathrm{G}_{2} / \mathrm{M}$ cells appear less phase bright, possibly due to the extent of PI intercalation within the cell, or due to the break down of the nucleus and condensation of the chromosomal nuclear material or that the cells are not as flattened by the cytospin procedure as cells in $G_{1}$. During the cell cycle process, typically the cells become larger as these progresses through each stage. $G_{2}$ stage cells should technically be the largest as cells continue to grow through the cell cycle, prior to mitosis. ${ }^{4}$ The diameters of 50 cells were measured using a ruler tool in the Omnic software for each phase. The group means were $24 \mu \mathrm{m}, 22 \mu \mathrm{m}$ and $19 \mu \mathrm{m}$ for cells in $\mathrm{G}_{1}, \mathrm{~S}$ and $\mathrm{G}_{2} / \mathrm{M}$ phase respectively and were found to be statistically different $(P<0.001)$ using a one-way analysis of variance (ANOVA) test in Graphpad Prism. Spectral acquisition of $\mathrm{G}_{2} / \mathrm{M}$ phase cells may have included a cell population richer in $\mathrm{M}$ phase cells than $G_{2}$ cells as in $M$ phase cell division would have occurred. The daughter cells would be smaller in size than cells in the rest of the cell cycle prior to mitosis ${ }^{4}$ however this would not correspond to the overall increased absorbance of the $G_{2} / M$ phase spectra. Due to cytospinning the cells onto the IR
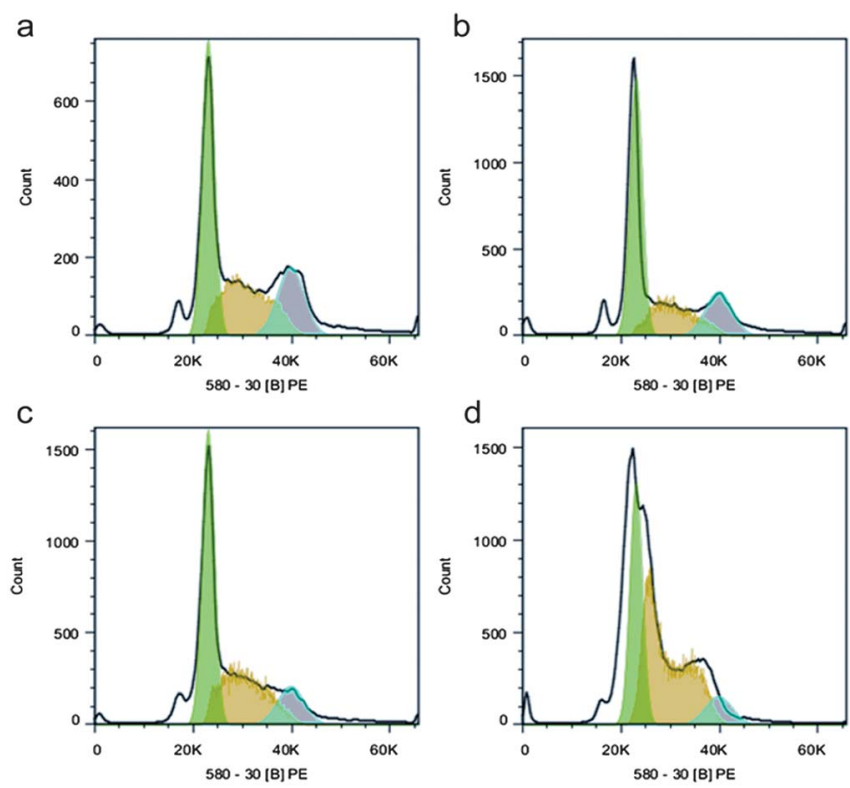

Fig. 2 FACS histogram plots of $\mathrm{G}_{1}$ (green), $\mathrm{S}$ (gold) and $\mathrm{G}_{2} / \mathrm{M}$ (blue) cell counts after 24 hours of drug exposure for (a) KF1 and (b) $5 F U$ (c) and (d) display the resulting plots after 72 hours of exposure for KF1 and $5 \mathrm{FU}$ respectively.

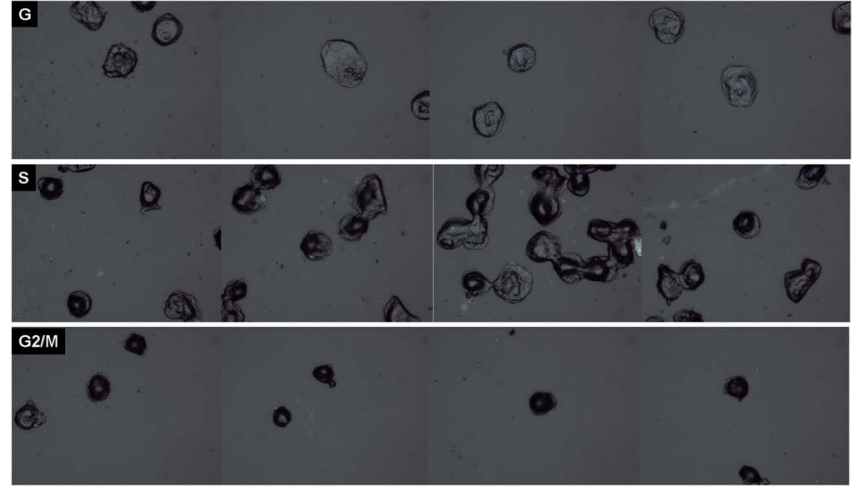

Fig. 3 Optical images of a selection of control cells for the 24 hour exposure time point prepared for spectroscopy measurements by cytospinning onto $\mathrm{CaF}_{2}$.

substrate, the morphology of the cells is less significant and assumptions about the natural size of the cells prior to processing for spectroscopy measurements cannot be made. The difference in PI concentration between cell phases, however, is probably not a factor, as the dye is applied after ethanol fixation. Research has shown that $\mathrm{G}_{2} / \mathrm{M}$ cells are said to be more rigid than $\mathrm{G}_{1}$ cells. ${ }^{13}$ This may be a plausible explanation as to why the $G_{1}$ cells appeared larger after cyto-spinning. $\mathrm{G}_{2} / \mathrm{M}$ cells, displaying more rigid properties than the $G_{1}$ or $S$ cells, may have remained relatively spherical when the centrifugal force was applied, whereas the $G_{1} / S$ cells flattened slightly more on impact.

In terms of RMieS scattering however, the difference in morphology of the cell phase types was very significant as the difference in cell size effects the Mie scattering profile as observed in the mean raw spectra (with standard deviation) in Fig. 4.

It was therefore important to utilise the RMieS correction algorithm on this dataset, resulting in much improved spectral quality in terms of absorbance values and peak positions. Control spectra for the 24 hour dataset were analysed in terms of $\mathrm{G}_{1}, \mathrm{~S}$ and $\mathrm{G}_{2} / \mathrm{M}$ phase and Fig. 5 displays the mean spectra directly after RMieS-EMSC correction (without vector normalisation).

Overall absorbance appeared to be greater in $\mathrm{G}_{2} / \mathrm{M}$ cells than in the other cell cycle spectra. This result favourably compared

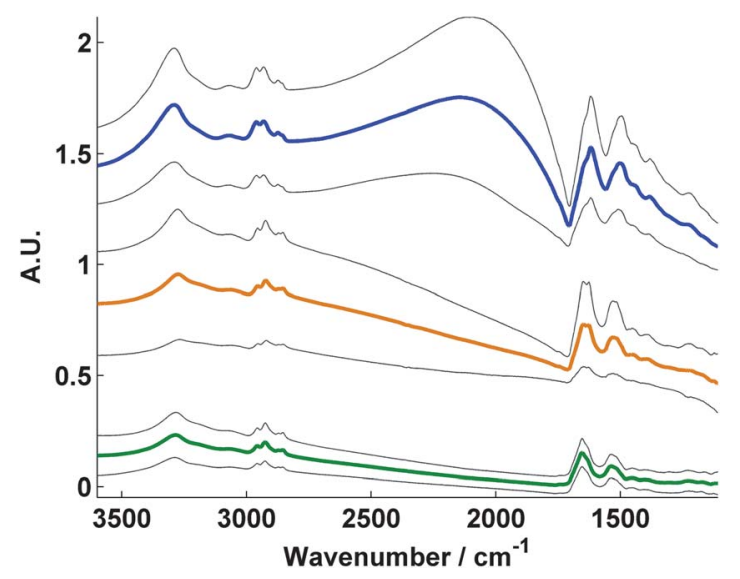

Fig. 4 The respective mean cell phase spectra \pm standard deviation for $\mathrm{G}_{1}$ (green), $\mathrm{S}$ (gold) and $\mathrm{G}_{2} / \mathrm{M}$ (blue), acquired from the non-drug treated control at the 24 hour time point. 


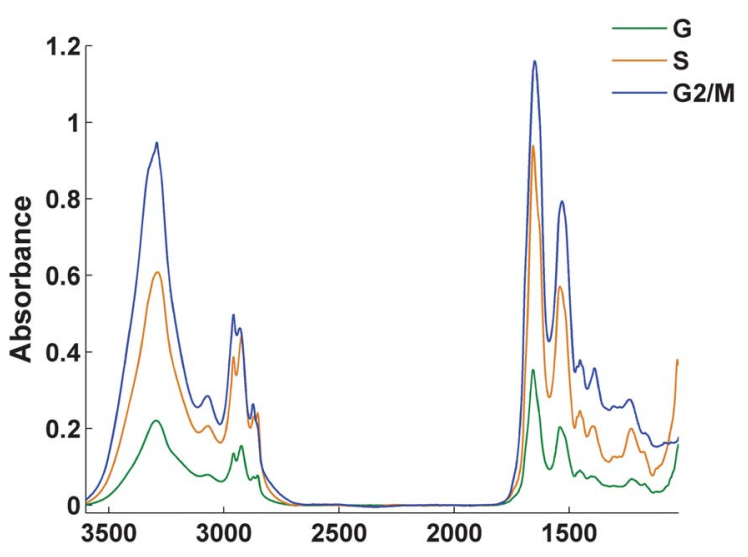

Fig. 5 Respective mean cell phase spectra for $\mathrm{G}_{1}, \mathrm{~S}$ and $\mathrm{G} 2 / \mathrm{M}$ acquired from the non-drug treated control at the 24 hour time point after RMieSEMSC correction.

with the research of Holman et al. ${ }^{2}$ who postulated that this observation was due to either more material in the cell, or thickness differences in $\mathrm{M}$ phase. In the second case there could be a greater path length for the IR beam to traverse. The $\delta_{\mathrm{s}}\left(\mathrm{CH}_{3}\right)$ peak at $\sim 1392 \mathrm{~cm}^{-1}$ is noticeably larger in the $\mathrm{G}_{2} / \mathrm{M}$ phase, an observation also noted by Holman et al. ${ }^{2}$ The agreeable observations suggest that the PI dye itself is not seriously affecting the associated chemistry of the cell cycle within the spectral bands of molecules, other than those associated with DNA.

\section{Cellular response after 24 hours of drug exposure}

The FACS cell count profiles displayed no apparent difference in cell accumulation in each phase after 24 hours of agent addition. Spectral analysis, however, was performed on $G_{1}$ phase cell spectra for the PI stained 24 hour drug exposure samples versus the control. Discrimination of different drug-treated cell spectra was achieved using PCA (Fig. 6). Due to the single-phase analysis where PI concentration and cell cycle chemistry remained a constant, the complexity of the dataset was reduced, such that the use of spectral derivatives or supervised chemometric techniques such as linear discriminant analysis (LDA) were not necessary to discriminate spectra, demonstrating the potential benefits of separating cell cycle chemistry from cell-drug response signals.
Although there is significant overlap between groups as is often seen at the single cell level (Fig. 6a) the drug-treated cell spectra are partially separable from the untreated cell control spectra through the PC1 axis, where the loading plot in PC1 predominantly highlights protein differences. There is also some discrimination of KF1 spectra from the CTL/5FU groups in PC3. The loadings in PC3 revealed a notable peak at $\sim 1700 \mathrm{~cm}^{-1}$. This peak resides near the protein region of the spectral fingerprint, although according to Dovbeshko et al. it may be associated with nucleic acid damage and repair; Stretching $\mathrm{C}=\mathrm{O}$ vibrations that are hydrogen-bonded (in guanine, thymine) are said to be connected with destruction of old H-bonds and creation of the new ones. ${ }^{14}$ It may be postulated that agent KF1 is interacting with the cellular DNA at this time point and it is reasonable to suggest that the drug is reaching the cell nucleus, suggesting the drug is active. The analysis of cells after the 24 hours of exposure will sample cells that are most likely within the process of cellular damage and repair.

Proliferating cells are generally more susceptible than resting cells to toxic and mutagenic effects of DNA-damaging agents, as DNA replication and chromosome segregation processes are easily disrupted by DNA damage. ${ }^{15}$ To prevent cells with damaged DNA from entering S-phase, signal transducers activate p53 and de-activate cyclin-dependent kinases in order to inhibit cell cycle progression. Cell cycle arrest can occur, which enables extra time for repair enzymes to work on the damaged DNA before cell cycle continuation. ${ }^{15,16}$ Activation and deactivation of signal transduction pathways are initiated by phosphorylation. In PC3 where KF1 is distinguishable from CTL/5FU clusters, there is a notable contribution in the corresponding loading plot (Fig. 6c) located around the lower spectral fingerprint region at $\sim 1240 \mathrm{~cm}^{-1}$ which is primarily associated with phosphate $\nu_{\text {as }}\left(\mathrm{PO}_{2}\right)$ stretching from phosphodiester groups of cellular nucleic acids. ${ }^{14}$

\section{Cellular response after 72 hours of drug exposure}

After 72 hours, however, cells that were likely to be affected by the chemotherapeutic agents would no longer be viable and would not have been part of the cell population. This is due to the removal of dead cells and debris during the sample processing. The flow-cytometry forward angle light-scatter gating would have removed small debris. Dead cells would also have been a

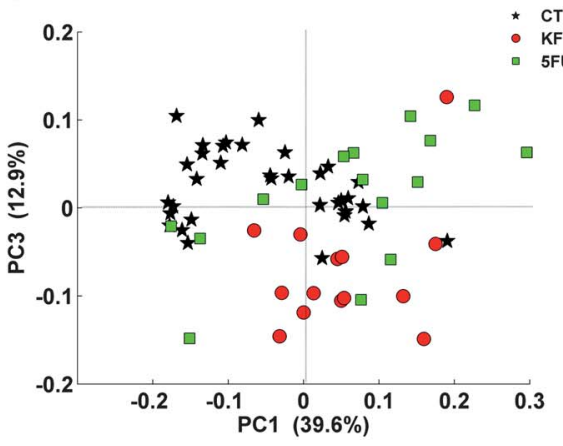

b

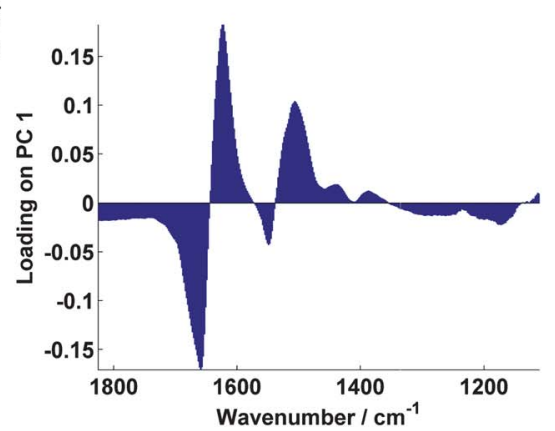

C

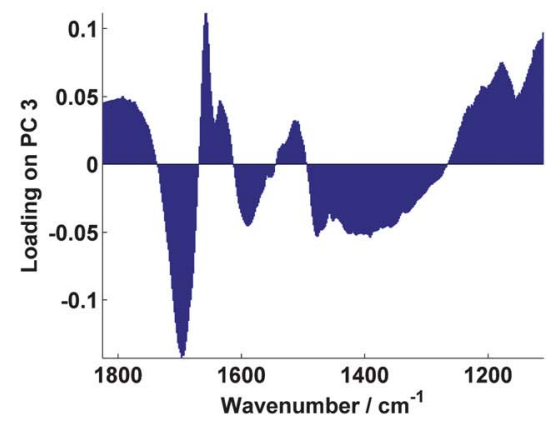

Fig. 6 PCA of cell spectra in $\mathrm{G}_{1}$ phase after 24 hours of drug exposure (a) with PC1 and PC3 loadings (b and c). 
gated-out due to a reduced DNA fluorescence signal from DNA breakdown in dead cells prior to chemical fixation. ${ }^{17,18}$ The cell populations studied in the 72 hour dataset therefore would have largely contained viable cells, either unaffected by the initial drug dose or cells that have undergone the repair process.

The 72 hour dataset, including all $G_{1}, S$ and $G_{2} / M$ phases for control, KF1 and 5FU cell spectra was analysed by PCA (Fig. 7). The resulting spread of data points appeared similar to
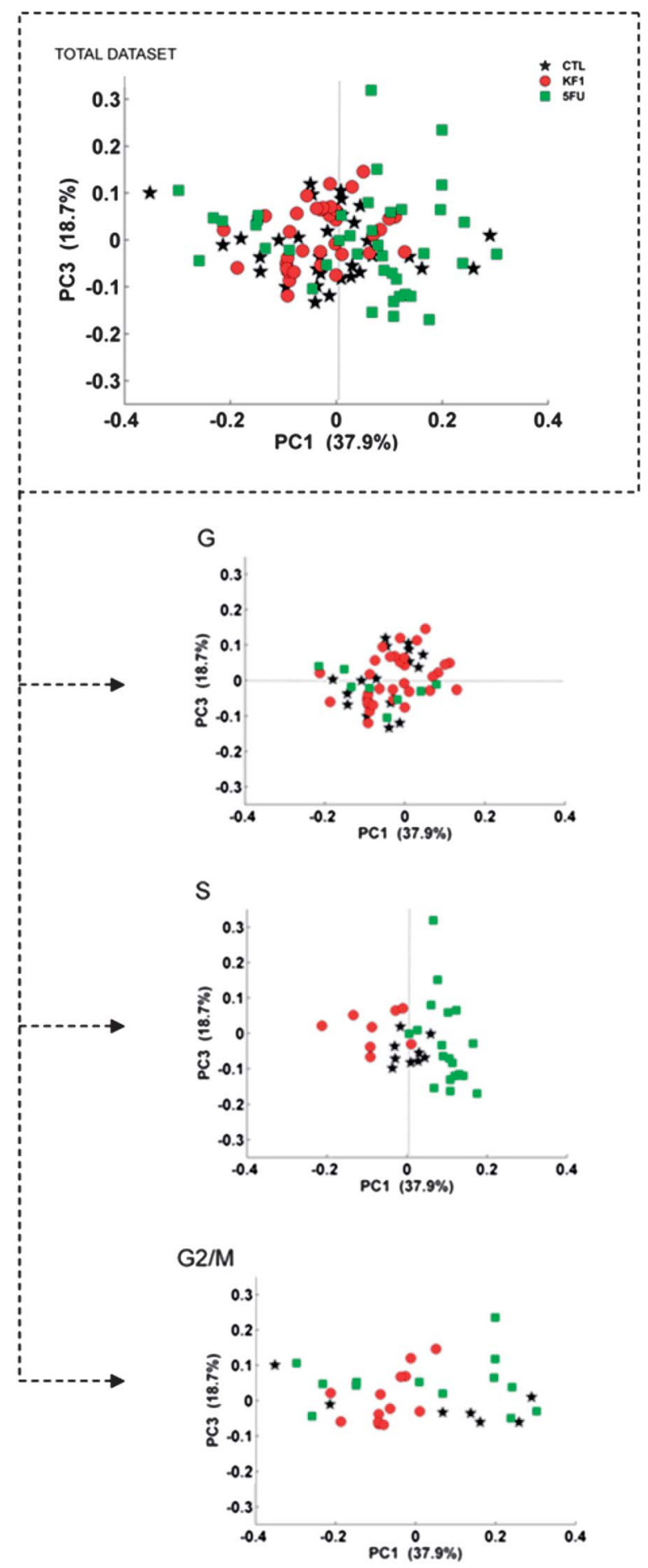

Fig. 7 PCA of total dataset (top) comprised of the respective cell cycle data from each phase; $G_{(1)}, S$ and $G_{2} / M$. previous research where similar plots were also observed in drug-treated ovarian cancer cell lines. ${ }^{1}$ For this A-498 cell line dataset, however, spectra corresponding to the individual cell cycle stage were known and are highlighted accordingly in the sub-plots below the total dataset figure (Fig. 7). It is clear that most of the variation in the main dataset cluster stemmed from the differences in cell chemistry in $S$ phase, without the requirement of spectral derivatives, or supervised discriminant analysis.

Analysis of the complete dataset loadings was not a viable option due to the variable extent of DNA conformational change from PI concentration from phase to phase. To validate this result, PCA was repeated using $\mathrm{S}$ phase group spectra alone. The same relationship was observed (Fig. 8), suggesting that the cell chemistry in KF1-treated cell spectra is anticorrelated with the 5FU-treated cell spectra. This result is in agreement with the FACS analysis, illustrating a significant change in the cell population profile of S phase after 72 hours of drug exposure to $5 \mathrm{FU}$ and the use of $5 \mathrm{FU}$ validates the FACS methodology. Although KF1 appears to cause a response in $G_{1}$ phase in the initial 24 hours after exposure, it does not appear to cause significant cell cycle arrest during $\mathrm{S}$ phase of the A-498 RCC cell line.

The prominent peak at $1700 \mathrm{~cm}^{-1}$ found in the PC loading of $\mathrm{G}_{1}$ phase (after 24 hours) associated with nucleic acid damage and repair (Fig. 6) was not present in the S phase PC2 loading plot (Fig. 8). Notable differences concerned the protein bands, and the nucleic acid-associated region of $1030-1240 \mathrm{~cm}^{-1}$. This detection may tentatively provide substantiation of a cellular response difference between the S-phase disruptive activity of $5 \mathrm{FU}$ compared to the gold-treated and control cells. 5FU is an analogue of uracil with a fluorine atom at the $\mathrm{C}-5$ position in place of hydrogen. Upon cellular entry, $5 \mathrm{FU}$ is converted to several active metabolites; fluorodeoxyuridine monophosphate (FdUMP), fluorodeoxyuridine triphosphate (FdUTP) and fluorouridine triphosphate (FUTP). These active metabolites disrupt RNA synthesis and the action of thymidine synthase (TS).

One suggestion for the large difference in protein signals between the active S-phase drug 5FU versus the control and goldtreated cells is activation of the intra-S-phase checkpoint that can block replication. The damage sensors for the intra-S checkpoint include a large set of checkpoint and repair proteins which are switched on by damage encountered during the $\mathrm{S}$ phase, or

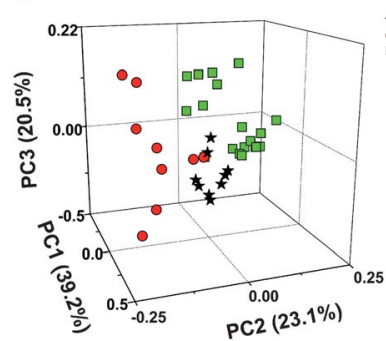

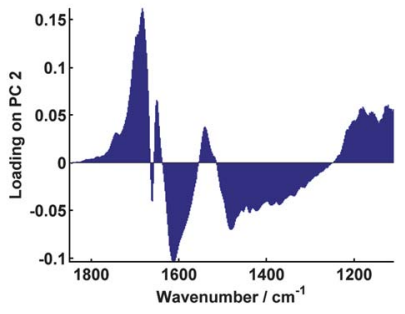

Fig. 8 PCA using S phase data only (a) and the PC2 loading plot that highlights the discriminatory chemical differences between the two different drug-treated cell populations. 
previously unrepaired damage that has escaped the $G_{1} / S$ checkpoint. ${ }^{16}$

\section{Conclusions}

Cellular response to the anticancer compounds could be detected after 24 hours of exposure. This highlights an advantage of the technique, and shows promise that an indication of drug efficacy may be detectable in a short time frame, in the context of high-throughput screening of a multidrug panel. Results at this time point have also raised the question as to what is the earliest time point an initial response may be detected by FTIR spectroscopy. An ideal way to monitor this would be to use a live cell experiment. Flow cytometry is a progressive field, particularly with the use of synchrotron radiation sources for single cell experiments. ${ }^{19-21}$ Water contributions, however, would dominate the signal unless a correction could account for its contribution, or a flow cytometry cell is well designed to limit the effects of water in the spectrum. Single cell infrared imaging in a live environment has been developed at the diffraction limit which could prove useful to monitor cell cycle change. ${ }^{22}$ This technique could also be used to determine whether the accumulated drug that is localised in the cell can reach such a high concentration that the drug or related bi-products are detectable in the IR. This is clearly another factor that needs to be taken into account when addressing IR signatures of cellular response to different drugs. ${ }^{23}$ For renal carcinoma, the cells are well known for their ability to efflux drugs at a rapid rate due to over-expression of plasma glycoprotein pumps on a level unrivalled to that of cells from other cancers. Therefore in this case we would not expect significant drug accumulation within the cells.

Alternatively Raman spectroscopy, which has an advantage over the infrared for liquid based experiments as there is no spectral water contribution does bring the risk that sample heating may affect cell viability. Despite this potential problem, recent applications of this methodology show promise ${ }^{24-26}$ and future studies will involve complementary Raman investigation.

Through the use of FACS analysis, sorting single cells by their progression phase in the cell cycle, it was possible to analyse differences largely due to drug effect by analysing one phase at a time. Where cluster patterns and chemical signatures could be interpreted by assessing same-phase spectra, a number of chemical differences agreed with the FACS analysis and the known mode of action of 5FU. The results including tentative band assignments would warrant further confirmation with alternative methods in order to be validated.

The necessary use of propidium iodide staining in this experiment, however, is not the most ideal proposal. As chemical fixation was used prior to staining, the staining should not have had too much of an effect on the cellular chemistry overall, such as the generation of toxic responses from live cells. It did, however, affect the detection of changes in nucleic acids; a highly important feature in monitoring cellular response to drugs. Cell spectra analysed across different phases would most likely involve difference in peaks associated with nucleic acids, due to the DNA conformational changes from the intercalation of different concentrations of PI dye.
It is still desirable to separate chemistry based on cell cycle differences from chemistry changes from cellular drug response as it now seems clear that cell cycle chemistry appears to inhibit or mask the effects of the different drugs. The next logical step in this line of research, therefore, would be to establish a method to define cell spectra to respective cell cycle phase without the use of staining and be applicable to cell lines of multiple origin. Isolation of cell cycle chemistry as a variable would enable clearer and more accurate analysis of drug response effects, with the aim of eventual discovery of reliable spectral biomarkers for the modality of novel drugs.

\section{Acknowledgements}

We acknowledge the EPSRC-RSC Analytical Science Studentship scheme and also the University of Manchester for financial and technical support for $\mathrm{CH}, \mathrm{FB}$ and GM. We acknowledge SOLEIL for provision of synchrotron radiation facilities (Proposal ID 20101043) and we would like to thank the EU for funding travel under the ELISA programme. We also thank Paul Dumas all staff at SOLEIL associated with the SMIS beamline.

\section{References}

1 K. R. Flower, I. Khalifa, P. Bassan, D. Demoulin, E. Jackson, N. P. Lockyer, A. T. McGown, P. Miles, L. Vaccari and P. Gardner, Analyst, 2011, 136(3), 498-507.

2 H. Y. N. Holman, M. C. Martin, E. A. Blakely, K. Bjornstad and W. R. McKinney, Biopolymers-Biospectroscopy Section, 2000, 57(6), 329-335.

3 A. Krishan, J. Cell Biol., 1975, 66(1), 188-193.

4 W. H. Elliott and D. C. Elliott, Biochemistry and Molecular Biology, Oxford University Press, 2001, pp. 495-502.

5 K. Flower and A. McGown, US Pat., 7732485 B2, 2010.

6 V. Vichai and K. Kirtikara, Nat. Protoc., 2006, 1, 1112-1116.

7 E. Gazi, J. Dwyer, J. Miyan, P. Gardner, C. Hart, M. Brown and N. W. Clarke, Biopolymers, 2005, 77, 18-30.

8 F. Lyang, E. Gazi and P. Gardner, Biomedical Applications of Synchrotron Radiation Infrared Microscopy, ed. D. Moss, RSC, 2010, ch. 5.

9 P. Dumas, F. Polack, B. Lagarde, O. Chubar, J. L. Giorgetta and S. Lefrancois, Infrared Phys. Technol., 2006, 49(1-2), 152160.

10 P. Bassan, H. J. Byrne, F. Bonnier, J. Lee, P. Dumas and P. Gardner, Analyst, 2009, 134(8), 1586-1593.

11 P. Bassan, A. Kohler, H. Martens, J. Lee, H. J. Byrne, P. Dumas, E. Gazi, M. Brown, N. Clarke and P. Gardner, Analyst, 2010, 135(2), 268-277.

12 D. B. Longley, D. P. Harkin and P. G. Johnston, Nat. Rev. Cancer, 2003, 3(5), 330-338.

13 M. A. Tsai, R. E. Waugh and P. C. Keng, Biophys. J., 1996, 70(4), 2023-2029.

14 G. I. Dovbeshko, N. Y. Gridina, E. B. Kruglova and O. P. Pashchuk, Talanta, 2000, 53(1), 233-246.

15 M. Ljungman, Environ. Mol. Mutagen., 2010, 51(8-9), 879889.

16 A. Sancar, L. A. Lindsey-Boltz, K. Unsal-Kacmaz and S. Linn, Annu. Rev. Biochem., 2004, 73, 39-85.

17 M. Kressel and P. Groscurth, Cell Tissue Res., 1994, 278(3), 549556.

18 K. A. Muirhead, E. D. Kloszewski, L. A. Antell and D. E. Griswold, J. Immunol. Methods, 1985, 77(1), 77-86.

19 M. J. Nasse, S. Ratti, M. Giordano and C. J. Hirschmugl, Appl. Spectrosc., 2009, 63(10), 1181-1186.

20 M. J. Tobin, L. Puskar, R. L. Barber, E. C. Harvey, P. Heraud, B. R. Wood, K. R. Bambery, C. T. Dillon and K. L. Munro, Vib. Spectrosc., 2010, 53(1), 34-38. 
21 Y. Oshima, T. Takenaka, H. Sato and C. Furihata, Progress in Biomedical Optics and Imaging - Proceedings of SPIE; 2010, vol. 11, p. 13.

22 M. J. Nasse, B. Bellehumeur, S. Ratti, C. Olivieri, D. Buschke, J. Squirrell, K. Eliceiri, B. Ogle, C. Schmidt Patterson, M. Giordanoc and C. J. Hirschmugl, Vib. Spectrosc., 2012, 60, 10-15.

23 C. Policar, J. B. Waern, M.-A. Plamont, S. Clède, C. Mayet, R. Prazeres, J.-M. Ortega, A. Vessières and A. Dazzi, Angew. Chem., 2011, 50(4), 860-864.
24 R. D. Snook, T. J. Harvey, E. Correia Faria and P. Gardner, Integr. Biol., 2009, 1(1), 43-52.

25 T. J. Harvey, C. Hughes, A. D. Ward, E. C. Faria, A. Henderson, N. W. Clarke, M. D. Brown, R. D. Snook and P. Gardner, J. Biophotonics, 2009, 2(1-2), 47-69.

26 T. J. Harvey, E. C. Faria, A. Henderson, E. Gazi, A. D. Ward, N. W. Clarke, M. D. Brown, R. D. Snook and P. Gardner, J. Biomed. Opt., 2008, 13(6), 064004. 